\title{
Validity of the updated European Society of Thoracic Surgeons staging guideline in lung cancer patients
}

\author{
Akif Turna, MD, PhD, FETCS, ${ }^{a}$ Hüseyin Melek, MD, ${ }^{\mathrm{b}}$ H. Volkan Kara, MD, MSc, ${ }^{\mathrm{a}}$ Burcu Kılıç, MD, ${ }^{\mathrm{a}}$ \\ Ezel Erşen, MD, ${ }^{a}$ and Kamil Kaynak, MD, FETCS ${ }^{\mathrm{a}}$
}

\section{ABSTRACT}

Objective: The European Society of Thoracic Surgeons (ESTS) has proposed a revised preoperative lymph node staging guideline for patients with potentially resectable non-small cell lung cancer (NSCLC). We aimed to assess the validity of this revised ESTS guideline and survival results in our patient cohort.

Methods: A total of 571 patients with potentially resectable NSCLC seen between January 2004 and November 2013 were included in the study. The preoperative mediastinal staging was performed by video-assisted cervical mediastinoscopy or video-assisted mediastinoscopic lymphadenectomy in all patients except those with peripheral cT1N0 nonadenocarcinoma tumors. Resection via thoracotomy or video-assisted thoracoscopic surgery was done in patients with no mediastinal lymph node metastasis. Surgical pathological results were compared with the ESTS staging guideline, and the validity of the guideline was tested.

Results: In this series, mediastinal lymph node metastasis was revealed preoperatively in 266 patients $(46.6 \%)$. A total of 305 patients underwent anatomic lung resection. The sensitivity, specificity, positive and negative predictive values, and accuracy of the guidelines were calculated as $95.0 \%$, $100 \%, 100 \%, 94.6 \%$, and $97.2 \%$, respectively.

Conclusions: The ESTS revised preoperative lymph node staging guidelines for patients with NSCLC seem to be effective and valid, and may provide high survival following resectional surgery. ( $\mathrm{J}$ Thorac Cardiovasc Surg 2018;155:789-95)

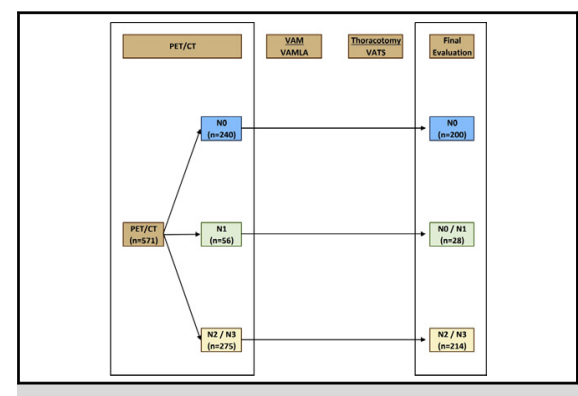

Mediastinal staging and final lymph node metastases results of the current series.

\section{Central Message}

Using the revised European Society of Thoracic Surgeons guideline to define the operable patients with non-small cell lung cancer is valid, may prevent most futile surgeries, and may provide a higher survival rate after curative resectional surgery.

\section{Perspective}

Selection of best treatment modality in patients with non-small cell lung cancer is of utmost importance. Using appropriate preoperative staging algorithm may provide appropriate selection of patients for resectional surgery. This study was conducted in order to investigate the validity of current ESTS staging guidelines as preoperative selection algorithm.

See Editorial Commentary page 796.
Lung cancer is responsible for the majority of the cancerrelated deaths in men and women in the United States as well as worldwide. ${ }^{1}$ Non-small cell lung cancer (NSCLC) accounts for nearly $85 \%$ of all lung cancers, ${ }^{2}$ and is

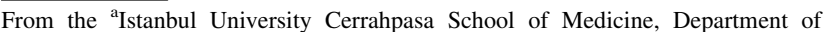

Thoracic Surgery, Fatih, İstanbul; and ${ }^{\mathrm{b}}$ Uludag University School of Medicine,

Department of Thoracic Surgery, Bursa, Turkey.

Read at the 24th European Conference on General Thoracic Surgery, Naples, Italy, 29

May 29-June 1, 2016.

Received for publication March 21, 2017; revisions received Sept 11, 2017; accepted

for publication Sept 18, 2017; available ahead of print Oct 27, 2017.

Address for reprints: Akif Turna, MD, PhD, FETCS, Bilginler Sok. No:12, A Blok,

Da:1, Sahrayicedid, Kadikoy, 34734 Istanbul, Turkey (E-mail: aturna@istanbul.

edu.tr).

$0022-5223 / \$ 36.00$

Copyright (C) 2017 by The American Association for Thoracic Surgery

https://doi.org/10.1016/j.jtcvs.2017.09.090
}

responsible for $23.6 \%$ of all cancer deaths in men and $13.8 \%$ of those in women. Most patients with NSCLC are diagnosed at an advanced stage and so do not undergo surgery during treatment, according to the evidence-based knowledge. $^{2}$

Accurate staging is of paramount importance in choosing the optimum treatment approach and predicting survival. ${ }^{3}$

Scanning this QR code will take you to the article title page. 


$\begin{array}{ll}\text { Abbreviations and Acronyms } \\ \text { CT } & \text { computed tomography } \\ \text { EBUS-TBNA }= & \text { endobronchial ultrasonography- } \\ & \text { transbronchial needle aspiration } \\ = & \text { European Society of Thoracic } \\ \text { ESTS } & \text { Surgeons } \\ \text { MLNM } & \text { mediastinal lymph node metastasis } \\ \text { NSCLC } & =\text { non-small cell lung cancer } \\ \text { PET } & =\text { positron emission tomography } \\ \text { TEMLA } & \text { transcervical extended mediastinal } \\ & \text { lymphadenectomy } \\ \text { VAM } & \text { video-assisted cervical } \\ & \text { mediastinoscopy } \\ \text { VAMLA } & \text { video-assisted mediastinoscopic } \\ & \text { lymphadenectomy } \\ \text { VATS } & =\text { video-assisted thoracoscopic } \\ & \text { surgery }\end{array}$

It is also a critical aspect of the diagnostic workup. Surgical resection has been shown to be the primary and best treatment for patients with stage IA-IIIA (T3N1) NSCLC. ${ }^{3,4}$ Mediastinal lymph node metastasis (MLNM) is the most important component of staging in NSCLC. . $^{3-5}$ Various invasive and noninvasive methods can be used to evaluate MLNM before lung resection. ${ }^{6}$ The European Society of Thoracic Surgeons (ESTS) published a preoperative mediastinal staging guideline in 2007 , and issued a revised version in 2014. . $^{7}$

According to the latest ESTS guideline, no mediastinal staging procedure (ie, endobronchial ultrasonographyguided transbronchial needle aspiration [EBUS-TBNA] or mediastinoscopy) is recommended in patients whom positron emission tomography (PET)-computed tomography (CT) shows no mediastinal metastasis and the tumor is peripherally located, is $<3 \mathrm{~cm}$ long in the longest axis, and has a nonadenocarcinoma histology. ${ }^{8}$ All other patients should undergo preoperative mediastinal staging. A negative EBUS-TBNA should be confirmed by mediastinoscopy in patients with a tumor larger than $\mathrm{T} 1$ with negative PET-CT findings. In addition, video-assisted mediastinoscopy (VAM) is recommended instead of conventional mediastinoscopy.

In the present study, we aimed to examine the validity of the revised ESTS preoperative mediastinal staging guideline.

\section{METHODS}

In this retrospective cohort study of prospectively recorded cases, the medical records of patients with NSCLC who had undergone surgical resection at our institution between January 2004 and June 2013 were analyzed. The preoperative workup included routine blood tests, pulmonary function tests with or without diffusion capacity of the lung for carbon monoxide and ventilation-perfusion lung scan, and blood gas analysis. Fiberoptic bronchoscopy, thoracic CT scan, and cranial magnetic resonance imaging were performed in most patients. PET-CT analysis was performed in 584 patients. Eleven patients found to have solitary extrathoracic distant (cranial/liver/adrenal) metastasis after surgery were excluded from our analysis, as were 3 patients who refused resection and 1 patient deemed at high risk because of medical comorbidities.

When a mediastinal lymph node station showing elevated fluorodeoxyglucose uptake compared with the mediastinal background and adjacent tissues was seen and/or the short axis of the hilar or mediastinal lymph node station was $>1 \mathrm{~cm}$, the patient was deemed to have mediastinal metastasis (ie, $\mathrm{cN} 1, \mathrm{cN} 2$, or $\mathrm{cN} 3$ ). Patient characteristics are summarized in Table 1 . In compliance with the ESTS guideline, ${ }^{8}$ all patients except the those with a tumor without adenocarcinoma histology $<3 \mathrm{~cm}$ and located in the peripheral third of the lung, with no hilar or mediastinal lymph node metastasis on PET-CT, underwent VAM ( $\mathrm{n}=428$ ) or video-assisted mediastinoscopic lymphadenectomy (VAMLA; $\mathrm{n}=143$ ), depending on the surgical team's experience and choice. Fourteen patients with PET-CT-positive mediastinal lymph node involvement underwent EBUS-TBNA before VAM/VAMLA. A mediastinal lymph node sampling VAM or at upper and lower paratracheal (numbers 2 and 4 both left and right), subcarinal (number 7) stations were performed in almost all patients. VAMLA was performed using a Linder-Dahan mediastinoscope (Richard Wolf, Knittlingen, Germany). During VAMLA, subcarinal and right lower paratracheal stations were completely dissected with fatty tissue. Upper paratracheal stations (station 2 both left and right) and left lower paratracheal (4L) were usually removed. In some patients, 10R, 10L, and paraesophageal lymph nodes were biopsied. The interval between VAM/VAMLA and pulmonary resection was $<45$ days in all cases. Preoperative evaluation of the mediastinum was supplemented by left anterior mediastinotomy $(n=29)$ or extended mediastinoscopy $(n=8)$ in patients with a tumor located at the left upper or main bronchus and in patients with enlarged $(>1 \mathrm{~cm}$ in the short axis $)$ and/or fluorodeoxyglucose-avid aorticopulmonary or anterior mediastinal lymph nodes (ie, stations 5 and 6).

According to our institutional strategy, patients with N0 disease were treated surgically without chemotherapy and/or radiotherapy). Patients with single-station $\mathrm{N} 2$ disease were given neoadjuvant chemo/radiotherapy and reevaluated for surgery. Patients with multiple-station N2 or N3 disease were treated with chemoradiotherapy only. Systematic mediastinal lymphadenectomy or lymph node sampling was performed in each patient following lung resection. The mean number of dissected mediastinal lymph nodes during and after surgery was 6 (range, 3-52), and the mean number of evaluated hilar or intrapulmonary lymph nodes (ie, N1) was 11.8 (range, 0-80). All patients underwent uniform staging to determine a final surgical-pathological stage, based on information obtained through resection lymphadenectomy and pathology examination according to the current TNM staging system. ${ }^{9}$ The final surgical-pathological stage of the patients who underwent surgery before 2009 was reconstructed according to a recently published staging system. ${ }^{9}$ Complete resection was defined as the removal of all detectable disease and histological confirmation of tumor-free resection margins.

\section{RESULTS}

A total of 305 patients underwent resectional surgery, 47 via videothoracoscopic surgery and 258 via anterior/ anterolateral/posterolateral thoracotomy. Pneumonectomy was performed in 63 patients $(20.7 \%)$, standard lobectomy was done in 211 patients $(69.2 \%)$, sleeve lobectomy was performed in 8 patients $(2.6 \%)$, bilobectomy was accomplished in 12 patients $(3.9 \%)$, and wedge resection/ segmentectomy was done in 11 patients $(3.6 \%)$. The 30-day postoperative mortality rate was $3.0 \%(\mathrm{n}=9)$. Complete resection was achieved in 291 cases $(95.4 \%)$. 
TABLE 1. Patient characteristics

\begin{tabular}{lrr}
\hline Characteristic & No. & $\%$ \\
\hline Sex & & \\
Male & 480 & 84.4 \\
Female & 91 & 15.9 \\
Side of tumor & & \\
$\quad$ Right & 302 & 52.8 \\
Left & 269 & 47.1 \\
Cell type & & \\
Squamous cell & 234 & 41.0 \\
Adenocarcinoma & 223 & 39.1 \\
Adenosquamous & 23 & 40.2 \\
Other & 91 & 15.9 \\
Stage & & \\
cIA & 68 & 11.9 \\
cIB & 52 & 9.1 \\
cIIA & 114 & 20.0 \\
cIIB & 40 & 7.0 \\
cIIIA & 275 & 2.5 \\
cIIIB & 14 & 1.4 \\
cIV & 8 & \\
\hline
\end{tabular}

The median number of resected lymph node stations during VAM or VAMLA was 5 (mean, 4.9). The mean number of lymph nodes per biopsy specimen was 30.8 (range, 8-107). PET-CT studies showed no mediastinal lymph node metastasis in 240 patients $(42.0 \%)$, $\mathrm{cN} 1$ disease in 56 patients $(9.8 \%)$, cN2 disease in 244 patients $(42.7 \%)$, and $\mathrm{cN} 3$ disease in 31 patients $(5.4 \%)$. Of the 240 patients with no mediastinal or hilar lymph node involvement on PET-CT, $200(83.3 \%)$ were found to have no mediastinal lymph node involvement.

Only those patients with no mediastinal lymph node involvement underwent resectional surgery. Of the 571 total patients, $305(53.4 \%)$ were treated surgically (Table 2$)$. The most frequent surgical pathological stage was IIA, seen in 78 patients $(25.5 \%)$. Moreover, 83 patients $(27.2 \%)$ were evaluated to have N1 disease (20 single-station and 63 multiple-station N1). Final histopathological examination found no mediastinal lymph node metastasis in 289 of

TABLE 2. Surgical-pathological stages of the patients who underwent resectional surgery

\begin{tabular}{lcc}
\hline Stage & No. & $\%$ \\
\hline IA & 67 & 21.9 \\
IB & 58 & 19.0 \\
IIA & 78 & 25.5 \\
IIB & 75 & 24.5 \\
IIIA & 25 & 8.2 \\
IV & 2 & 0.5 \\
Total & 305 & 100 \\
\hline
\end{tabular}

305 patients who underwent resection (94.7\%) (Figure 1). A total of 266 patients had mediastinal lymph node involvement after VAM/VAMLA (Figure 1). Among the patients found to have no mediastinal lymph nodes after VAM or VAMLA, $16(4.0 \%)$ were diagnosed with $\mathrm{N} 2$ disease on final pathological evaluation (Figure 1). Thus, a total of 292 patients were found to have mediastinal lymph node metastasis (N2/N3) after VAM/VAMLA and mediastinal lymph node dissection. In patients with a peripherally located tumor (T1) and with no mediastinal lymph node involvement on PET-CT (ie, cN0), the negative predictive value was $95.6 \% ; 1$ case of $\mathrm{N} 2$ was disclosed by VAM/VAMLA, and another was revealed on resectional surgery (Figure 1). The false negativity rate was $16.7 \%$. Similarly, 214 of 275 patients $(77.8 \%$ ) with $\mathrm{cN} 2 / 3$ disease were evaluated to have $\mathrm{N} 2$ or N3 after VAM/VAMLA and/or resectional surgery (Figure 1).

Regarding the importance of $\mathrm{cN} 1$ indicated on PET-CT, 24 of 56 patients $(42.9 \%)$ were found to have mediastinal lymph node involvement after VAM/VAMLA (Figure 1). The sensitivity and specificity of PET-CT evaluation for mediastinal staging were $84.3 \%$ and $76.7 \%$, respectively (Table 3). On the other hand, when ESTS guidelines were evaluated as a staging algorithm, the accuracy was $97.2 \%$ (Table 3). Figure 2 shows the results using the revised staging algorithm. Had we not followed the ESTS guideline for preoperative mediastinal staging, 296 patients would have undergone surgery. Of 206 patients who were cN0 and found to have no mediastinal lymph node metastasis, 11 were evaluated to have $\mathrm{N} 2$ disease after resectional surgery and lymph node dissection. Among the 67 patients with $\mathrm{cN} 2$ involvement on PET-CT, 61 were found to have no mediastinal lymph node involvement. The negative predictive value of VAM/VAMLA was $94.6 \%$ in patients with $\mathrm{cN} 0$ and $91.0 \%$ in those with $\mathrm{cN} 2$ (Table 4). Considering final pathological evaluation when the preoperatively discovered lymph node metastases were added, 202 of 240 patients $(84.2 \%)$ who were clinically N0 were found to have N0 disease, whereas one-half of the patients with $\mathrm{cN} 1$ were found to have pN1 (Figure 3). The positive predictive value of PET-CT for N2/N3 disease was $74.5 \%$ (Figure 3 ).

Regarding the possible impact of surgical approach on the results, we found out that 1 of 26 patients with cIA $(3.8 \%)$ who underwent surgery by VATS was N2 after VAMLA, whereas 3 cases of mediastinal lymph node involvement was found in 42 patients $(7.1 \%)$ who underwent thoracotomy $(P=.504)$.

\section{DISCUSSION}

Although PET-CT is of paramount importance in mediastinal staging in patients with potentially operable NSCLC, it is suboptimal, and the ESTS preoperative mediastinal staging guideline provides excellent results 


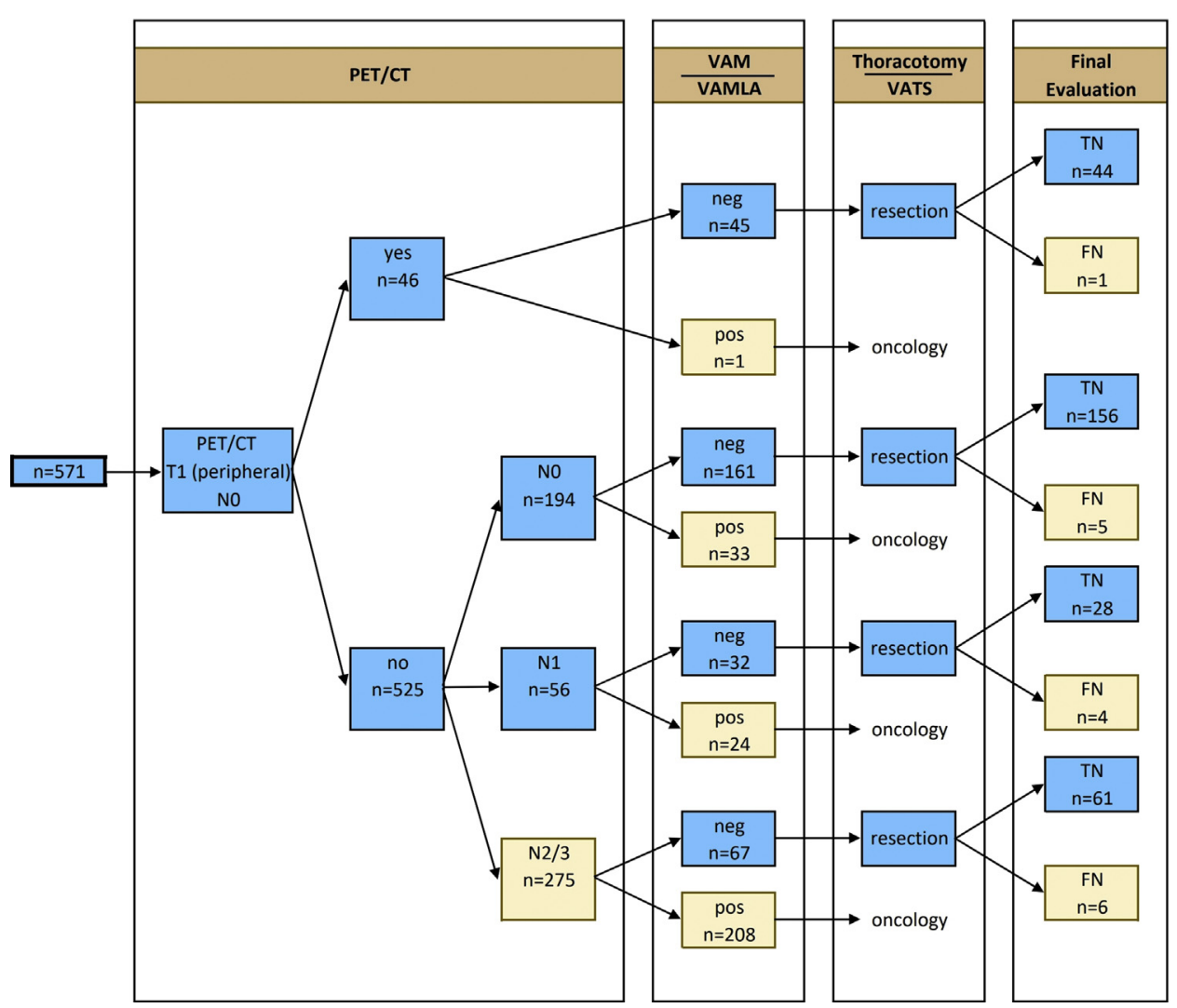

FIGURE 1. Schematic summary of mediastinal status of patients according to PET-CT, mediastinal evaluation, and surgical pathological evaluation. PET, Positron emission tomography; $C T$, computed tomography; VAM, video-assisted cervical mediastinoscopy; VAMLA, video-assisted mediastinoscopic lymphadenectomy; VATS, video-assisted thoracoscopic surgery; $T N$, true negative; $F N$, false negative.

for patient selection and helps discriminate patients with prior $\mathrm{N} 2$ disease. Because patients with multiple ipsilateral (multiple N2) or contralateral (N3) mediastinal lymph node involvement cannot benefit from resectional surgery without chemotherapy and/or radiotherapy,${ }^{10}$ all appropriate measures should be taken to identify expected or unforeseen N2 disease before surgery. Mediastinoscopy, which was introduced by Carlens in $1959,{ }^{11}$ has been accepted as a gold standard for invasive mediastinal staging of patients with potentially operable NSCLC. However, there is no clear standard protocol for mediastinoscopy, and negative predictive value as low as $80 \%$ have been reported. ${ }^{12}$ Nonetheless, we previously reported that mediastinoscopy could disclose $\mathrm{N} 2$ disease in approximately $7.5 \%$ of patients with even cN0 disease. ${ }^{13}$ On the other hand, the positive predictive value of PET-CT is only approximately $50 \%,{ }^{14}$ and if positive results are taken as true, then one-half of the PET-positive patients could not benefit from potentially curative surgical resection.

VAM was introduced in 1995, and a meta-analysis of 108 papers covering VAM suggested that VAM is associated with better and clearer visibility and a better opportunity to perform nodal dissection. ${ }^{8}$ A report that VAM allows more lymph nodes from the subcarinal region has been also published..$^{15}$ On the other hand, given the reported rate of lymph node positivity after resection in PET-CT-negative patients of $17 \%$ to $21 \%,{ }^{16,17}$ depending on PET-CT alone in mediastinal staging could result in futile resections of tumors with $\mathrm{N} 2$ or N3 disease. In our study, the false-positive and false-negative rates for PET-CT were $22.2 \%$ and $16.7 \%$, respectively. The ESTS preoperative mediastinal staging guideline suggests that direct surgery without mediastinoscopy

TABLE 3. Accuracy rates of PET-CT alone and ESTS guidelines in mediastinal staging

\begin{tabular}{|c|c|c|c|c|c|}
\hline $\begin{array}{c}\text { Preoperative mediastinal } \\
\text { evaluation }\end{array}$ & $\begin{array}{l}\text { Negative predictive } \\
\text { value, } \%(95 \% \mathrm{CI})\end{array}$ & $\begin{array}{l}\text { Positive predictive } \\
\text { value, } \%(95 \% \mathrm{CI})\end{array}$ & $\begin{array}{l}\text { Sensitivity, } \\
\%(95 \% \text { CI })\end{array}$ & $\begin{array}{l}\text { Specificity, } \\
\%(95 \% \text { CI })\end{array}$ & $\begin{array}{l}\text { Accuracy, } \\
\%(95 \% \text { CI })\end{array}$ \\
\hline Routine PET-CT & $83.3(77.8-87.7)$ & $77.8(72.4-82.5)$ & $84.3(79.1-88.4)$ & 76.7 (70.9-81.5) & $80.3(75.0-85.1)$ \\
\hline ESTS guidelines, 2014 & 94.1 (90.5-96.6) & $100(98.2-100)$ & $94.6(91.1-96.9)$ & $100(98.1-100)$ & $97.2(93.7-99.7)$ \\
\hline
\end{tabular}

CI, Confidence interval; PET, positron emission tomography; CT, computed tomography; ESTS, European Society of Thoracic Surgeons. 


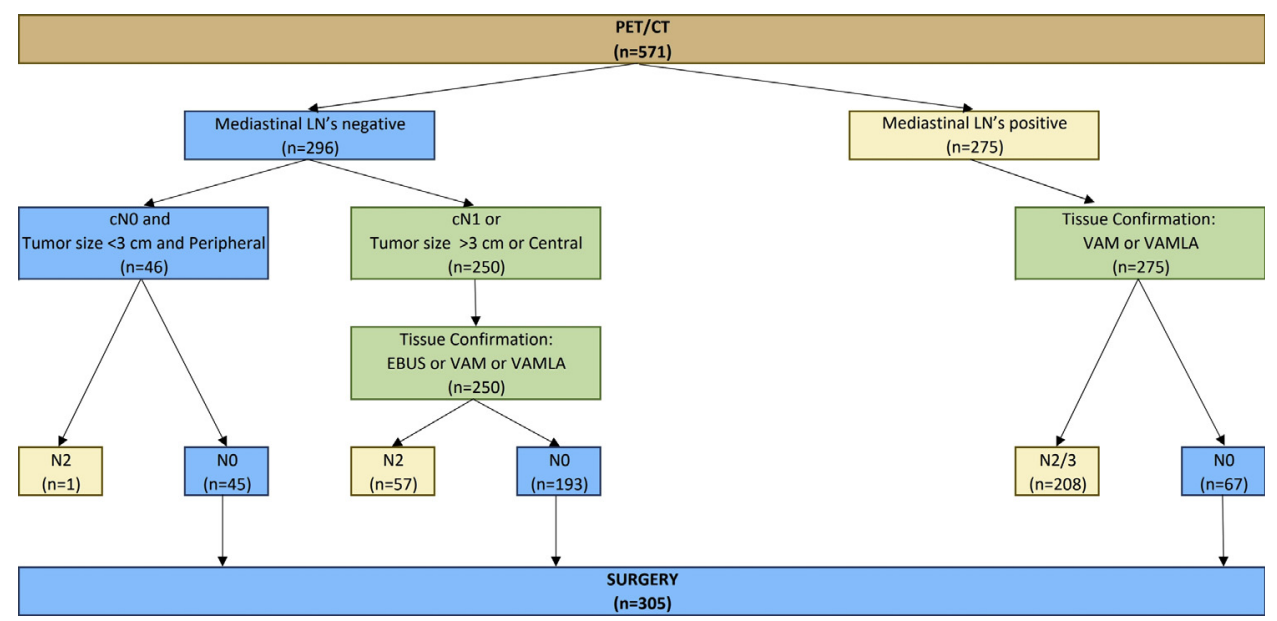

FIGURE 2. Number of patients and results of staging algorithm. PET, Positron emission tomography; $C T$, computed tomography; $L N$, lymph node; $E B U S$, endobronchial ultrasonography; VAM, video-assisted mediastinoscopy; VAMLA, video-assisted mediastinoscopic lymphadenectomy.

can be performed only in patients without suspect lymph nodes detected by PET and/or CT with tumors $<3 \mathrm{~cm}$ in the outer third of the lung. We have complied with ESTS staging guidelines for more than 13 years. Videomediastinoscopy has been performed for 7 years at our institution. For the patients with peripheral $\mathrm{T} 1$ tumors, the negative predictive value of VAM/VAMLA was $97.8 \%$. The new ESTS guideline suggests that VAM is recommended in patients with $\mathrm{cN} 1$ involvement on PET-CT owing to the high possibility of $\mathrm{pN} 2$ disease partly attributable to poor spatial resolution of PET-scanning. In our series, $42.9 \%$ of patients with $\mathrm{cN} 1$ involvement were found to have N2 disease; however, we included patients with hilar tumors in this subgroup analysis. Nevertheless, this finding also supports a guidelines algorithm. In our series, 46 patients with a cT1N0 tumor underwent VAM or VAMLA since the histopathology was NSCLC, and it was not possible to exclude the histology of adenocarcinoma, and the ESTS guideline recommends performing VAM or VAMLA in these patients. Forty-four of those 44 patients were found to have no mediastinal lymph node involvement after VAM/VAMLA and mediastinal lymph node dissection.

According to Yue and colleagues, ${ }^{18}$ surgical resection following International Association for Study of Lung Cancer, National Comprehensive Cancer Network, American College of Surgeons Oncology Group, or
RADIANT (Randomized Double-Blind Trial in Adjuvant NSCLC with Tarceva) guidelines had no affect on overall survival. ${ }^{17}$ We did not compare different guidelines in our study; however, there are no major differences in terms of preoperative mediastinal staging among the various guidelines. ${ }^{4,8,18}$ Despite the similarities in the published guidelines, there are differences between surgeons in the United States and Europe regarding the preoperative and intraoperative N2 nodal assessment. ${ }^{19}$ North American surgeons usually perform preoperative lymph node staging to disclose N2 nodes before resection, whereas European surgeons often identify them at the time of planned resection and do not view $\mathrm{N} 2$ as a contraindication for surgery. ${ }^{19}$ Rocco and colleagues ${ }^{19}$ reported that despite similar distributions of $\mathrm{T}$ stage, only $8 \%$ and $16 \%$ of patients were reported to have N2 disease after lobectomy and pneumonectomy, respectively, in the Society for Thoracic Surgeons database, compared with $14 \%$ and $30 \%$ in the ESTS registry.

Regarding the lymph node dissection recommended by the ESTS guideline, at least 3 mediastinal lymph node stations were sampled or dissected by videomediastinoscopy or VAMLA (median number of dissected lymph, 5). Kuzdzal and colleagues ${ }^{20}$ developed technique of invasive bilateral mediastinal lymph node dissection, named as transcervical extended mediastinal lymphadenectomy (TEMLA). TEMLA enables complete resection

TABLE 4. Performance of video-assisted mediastinoscopy or video-assisted mediastinoscopic lymphadenectomy in mediastinal staging

\begin{tabular}{lcccc}
\hline \multicolumn{1}{c}{ cN } & $\begin{array}{l}\text { Negative predictive } \\
\text { value, } \% \mathbf{( 9 5} \% \mathbf{C I})\end{array}$ & $\begin{array}{c}\text { Positive predictive } \\
\text { value, \% } \mathbf{( 9 5} \% \mathbf{C I})\end{array}$ & Sensitivity, \% (95\% CI) & Specificity, \% (95\% CI) \\
\hline cN0 & $94.9(90.9-97.3)$ & $100.0(96.0-100)$ & $97.1(93.7-98.8)$ & $100.0(96.6-100)$ \\
cN2/3 & $91.0(80.9-96.3)$ & $100.0(90.1-100)$ & $97.2(93.7-98.8)$ & $100.0(96.5-100)$ \\
\hline
\end{tabular}

CI, Confidence interval. 


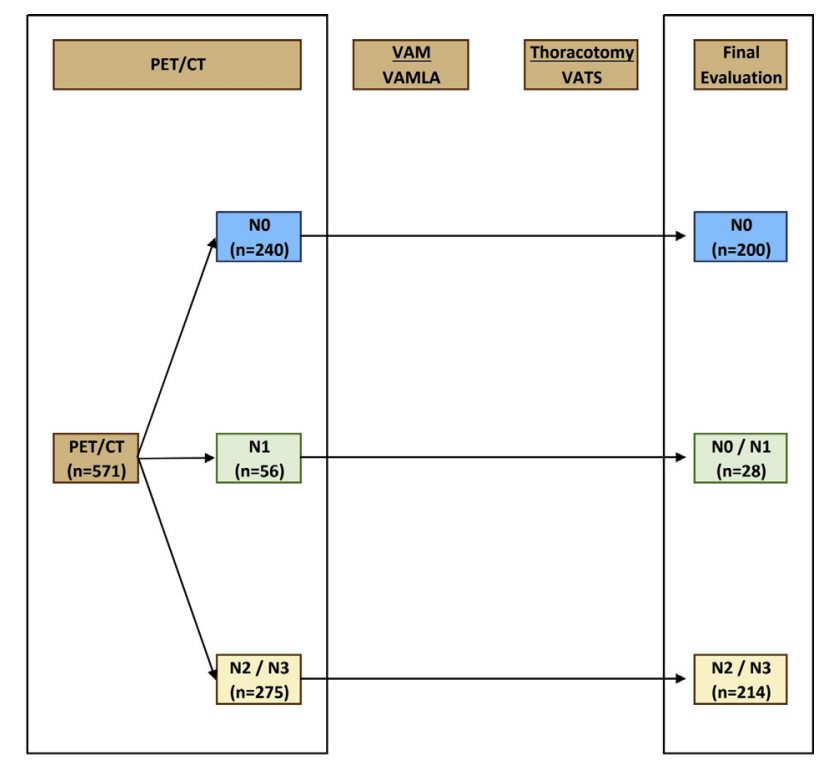

FIGURE 3. The surgical-pathological findings of lymph nodes according to preoperative lymph node metastases based on PET-CT. PET, Positron emission tomography; $C T$, computed tomography; VAM, video-assisted cervical mediastinoscopy; VAMLA, video-assisted mediastinoscopic lymphadenectomy; VATS, video-assisted thoracoscopic surgery.

of all mediastinal lymph nodes from stations $2 \mathrm{~L}, 2 \mathrm{R}, 3$, 4R, 4L, 7, 8, and 9, including aorticopulmonary and anterior mediastinal lymph nodes. The technique is an accurate modality in preoperative NSCLC, with the advantages of radical lymphadenectomy, which precludes the need for lymph node dissection during or after anatomic lung resection. However, TEMLA is technically demanding and requires a special sternum elevator. VAMLA is somewhat equivalent to TEMLA, with an additional advantage of being relatively less technically difficult. $^{21}$ Moreover, we previously showed that VAMLA seems to provide better preoperative invasive staging, with higher sensitivity, negative predictive value, and accuracy when performed before planned resectional surgery in patients with operable NSCLC. ${ }^{22}$ It also has been reported to apparently prolong survival in patients with NSCLC. The relatively higher survival (mean, 97 months) could be attributable to this phenomenon. Although VAMLA was associated with better survival compared with standard mediastinoscopy before resection, there is no evidence indicating a difference between VAM and VAMLA in terms of sensitivity, specificity, negative predictive value, accuracy, and survival of patients who underwent resectional surgery. Nevertheless, better lymph node staging before surgery leads to a fewer patients with mediastinal lymph node metastasis undergoing resectional surgery. In our study, only 16 out of an evaluated 571 patients were found to have mediastinal lymph node metastasis after final pathological evaluation.
Given the report by Albain and colleagues ${ }^{10}$ demonstrating the futility of resection of lung cancer with mediastinal lymph node metastasis, we refer all patients with mediastinal lymph node metastasis to oncologic therapy as recommended by the guidelines. Regarding the complication rate associated with VAM/VAMLA, 8 patients had dysphonia after VAM/VAMLA (1.7\%), possibly due to recurrent nerve edema or injury. Five patients were referred to vocal cord centralization, and dysphonia was resolved in all patients. One patient had major bleeding, necessitating sternotomy for repairing aorta. There was no mortality attributable to VAM/ VAMLA.

It is plausible to suggest that PET-CT evaluation might become more accurate due to technological advances. We did not analyze this possibility, however, because the false-negative rate in first 2 years did not change compared with recent results (data not shown). Similarly, our VATS program was initiated in 2011. However, we performed systematic lymph node dissection in all patients who underwent VATS lobectomy to eliminate any potential doubt regarding the technical possibility of lymph node dissection during VATS in early years.

This study has some limitations, associated with its retrospective cohort design analyzing a single center's experience. Videomediastinoscopy or VAMLA was performed based on the surgeon's preference. We did not compare the results of these 2 methods; however, it is plausible to expect slight differences in accuracy between the 2 methods. Moreover, only 14 patients in our cohort underwent EBUS-TBNA, owing to availability and reimbursement issues. EBUS-TBNA has been recently approved for reimbursement. In addition, since all negative EBUS-TBNA results are recommended to be confirmed by VAM or VAMLA in patients with other than cT1N0 NSCLC, it prolongs the preresection evaluation period, so most patients underwent VAM or VAMLA without previous EBUS-TBNA, for most ESTS guidelines recommend EBUS-TBNA in the facilities where the device and experienced physicians are available. However, EBUS-TBNA and videomediastinoscopy are interchangeably recommended for patients with $\mathrm{cN} 2$ disease. ${ }^{6}$ The number of VATS resections was also low in our series. We initiated our VATS lobectomy program in 2011. Most patients who underwent VATS lobectomy were the cases treated during our learning curve. In recent years, $>60 \%$ of all resections are performed via a videothoracoscopic approach. Finally, we did not compare different guidelines to identify the most effective guidelines in terms of accuracy and survival.

The recently revised ESTS guidelines seem to provide very high negative predictive value, accuracy, and sensitivity in preoperative mediastinal staging. Further comparative studies are warranted to confirm our results. 


\section{Conflict of Interest Statement}

Authors have nothing to disclose with regard to commercial support.

\section{References}

1. International Agency for Research on Cancer; World Health Organization. In: Stewart BW, Wild CW, eds. World Cancer Report 2014. Lyon, France: WHO Press; 2014:350-60.

2. American Cancer Society. Cancer facts and figures 2016. Available at: http:// www.cancer.org/research/cancerfactsstatistics/cancerfactsfigures2016/. Accessed August 31, 2017

3. Vallières E, Shepherd FA, Crowley J, Van Houtte P, Postmus PE, Carney D, et al. International Association for the Study of Lung Cancer International Staging Committee and participating institutions. The IASLC Lung Cancer Staging Project: proposals regarding the relevance of TNM in the pathologic staging of small cell lung cancer in the forthcoming (seventh) edition of the TNM classification for lung cancer. J Thorac Oncol. 2009;4:1049-59.

4. Howington JA, Blum MG, Chang AC, Balekian AA, Murthy SC. Treatment of stage I and II non-small cell lung cancer: diagnosis and management of lung cancer, 3rd ed: American College of Chest Physicians evidence-based clinical practice guidelines. Chest. 2013;143(5 Suppl):e278S-313S

5. Asamura H, Chansky K, Crowley J, Goldstraw P, Rusch VW, Vansteenkiste JF, et al. The International Association for the Study of Lung Cancer Lung Cancer Staging Project: proposals for the revision of the $\mathrm{N}$ descriptors in the forthcoming 8th edition of the TNM Classification for Lung Cancer. J Thorac Oncol. 2015;10:1675-84.

6. Silvestri GA, Gonzalez AV, Jantz MA, Margolis ML, Gould MK, Tanoue LT, et al. Methods for staging non-small cell lung cancer: diagnosis and management of lung cancer, 3rd ed: American College of Chest Physicians evidence-based clinical practice guidelines. Chest. 2013;143(5 Suppl):e211S-50S.

7. De Leyn P, Lardinois D, Van Schil PE, Rami-Porta R, Passlick B, Zielinski M, et al. ESTS guidelines for preoperative lymph node staging for non-small cell lung cancer. Eur J Cardiothorac Surg. 2007:32:1-8.

8. De Leyn P, Dooms C, Kuzdzal J, Lardinois D, Passlick B, Rami-Porta R, et al. Revised ESTS guidelines for preoperative mediastinal lymph node staging for non-small-cell lung cancer. Eur J Cardiothorac Surg. 2014;45:787-98.

9. Groome PA, Bolejack V, Crowley JJ, Kennedy C, Krasnik M, Sobin LH, et al. The IASLC Lung Cancer Staging Project: validation of the proposals for revision of the $\mathrm{T}, \mathrm{N}$, and $\mathrm{M}$ descriptors and consequent stage groupings in the forthcoming (seventh) edition of the TNM classification of malignant tumors. J Thorac Oncol. 2007;2:694-705.

10. Albain KS, Swann RS, Rusch VW, Turrisi AT III, Shepherd FA, Smith C, et al. Radiotherapy plus chemotherapy with or without surgical resection for stage III non-small-cell lung cancer: a phase III randomised controlled trial. Lancet. 2009; $374: 379-86$.
11. Carlens E. Mediastinoscopy: a method for inspection and tissue biopsy in the superior mediastinum. Dis Chest. 1959;36:343-52.

12. Fibla JJ, Molins L, Simon C, Perez J, Vidal G. The yield of mediastinoscopy with respect to lymph node size, cell type, and the location of the primary tumor. $J$ Thorac Oncol. 2006;1:430-3.

13. Gürses A, Turna A, Bedirhan MA, Ozalp T, Kocatürk C, Demir A, et al. The value of mediastinoscopy in preoperative evaluation of mediastinal involvement in non-small-cell lung cancer patients with clinical NO disease. Thorac Cardiovasc Surg. 2002;50:174-7.

14. Gonzalez-Stawinski GV, Lemaire A, Merchant F, O'Halloran E, Coleman RE Harpole DH, et al. A comparative analysis of positron emission tomography and mediastinoscopy in staging non-small cell lung cancer. J Thorac Cardiovasc Surg. 2003;126:1900-5.

15. Sayar A, Çitak N, Metin M, Turna A, Pekçolaklar A, Kök A, et al Comparison of video-assisted mediastinoscopy and video-assisted mediastinoscopic lymphadenectomy for lung cancer. Gen Thorac Cardiovasc Surg. 2011;59:793-8

16. Gould MK, Kuschner WG, Rydzak CE, Maclean CC, Demas AN, Shigemitsu H et al. Test performance of positron emission tomography and computed tomography for mediastinal staging in patients with non-small-cell lung cancer: a meta-analysis. Ann Intern Med. 2003;139:879-92.

17. de Langen AJ, Raijmakers P, Riphagen I, Paul MA, Hoekstra OS. The size of mediastinal lymph nodes and its relation with metastatic involvement: a meta-analysis. Eur J Cardiothorac Surg. 2006;29:26-9.

18. Yue D, Gong L, You J, Su Y, Zhang Z, Zhang Z, et al. Survival analysis of patients with non-small cell lung cancer who underwent surgical resection following 4 lung cancer resection guidelines. BMC Cancer. 2014;14:422.

19. Rocco G, Nason K, Brunelli A, Varela G, Waddell T, Jones DR. Management of stage IIIA (N2) non-small cell lung cancer: a transatlantic perspective. Ann Thorac Surg. 2016;101:1247-50.

20. Kuzdzał J, Zieliński M, Papla B, Urbanik A, Wojciechhowski W, Narski M, et al The transcervical extended mediastinal lymphadenectomy versus cervical mediastinoscopy in non-small cell lung cancer staging. Eur J Cardiothorac Surg. 2007;31:88-94.

21. Zieliński M. Video-assisted mediastinoscopic lymphadenectomy and transcervical extended mediastinal lymphadenectomy. Thorac Surg Clin. 2012;22: 219-25.

22. Turna A, Demirkaya A, Özkul S, Öz B, Gürses A, Kaynak K. Video-assisted mediastinoscopic lymphadenectomy is associated with better survival than mediastinoscopy in patients with resected non-small cell lung cancer. $J$ Thorac Cardiovac Surg. 2013;146:774-80.

Key Words: non-small cell lung cancer, ESTS guideline, $\mathrm{N} 2$ disease, mediastinoscopy, mediastinal staging 